\title{
The Role of Nickel-titanium Shape Memory Alloy Embracing Fixator in Determination of the Implantation Angle of Hip Tumor Prosthesis Stem Following Tumor Resection and the Analysis of Its Efficacy: a Retrospective Study
}

\section{Yang Wang}

Changhai Hospital

\section{Panyu Zhou}

Changhai Hospital

\section{Demeng Xia}

Changhai Hospital

Yunyun Wang

Qingdao University

Sheng Wang

Changhai Hospital

Hongyue Zhang

Changhai Hospital

Shuogui Xu ( $\sim 18516116672 @ 163 . c o m)$

Changhai Hospital https://orcid.org/0000-0001-5926-4391

\section{Research article}

Keywords: Ni-Ti shape memory alloy, hip tumor prosthesis stem, implantation angle

Posted Date: January 5th, 2021

DOl: https://doi.org/10.21203/rs.3.rs-138932/v1

License: (a) (1) This work is licensed under a Creative Commons Attribution 4.0 International License.

Read Full License 


\section{Abstract}

Background: To explore the role of nickel-titanium(NiTi) shape memory alloy embracing fixator in determination of implantation angle of hip tumor prosthesis stem and analyze its efficacy.

Methods: 36 patients with proximal femur tumor were treated with extended tumor resection and prosthetic replacement. 14 patients received prosthetic replacements with the embracing fixators fixing between the junction of the prosthesis stem and the femur temporarily, while the other 22 patients received the same replacements but without the fixators. Following aspects were compared: occurrence of complications, limb function and active hip ROM.

Results: There are fewer cases of hip dislocation in the group received prosthetic replacements with the use of embracing fixators. Occurrence of deep infection presented no difference between the two groups. Better limb function and higher active range of motion (ROM) on abduction or flexion were also found in the group using embracing fixators.

Conclusion: $\mathrm{Ni}-\mathrm{Ti}$ shape memory alloy embracing fixator plays a key part in assisting the accurate implantation angle of the prosthesis stem in the prosthetic replacement. The prosthesis stem can be adjusted to the optimal angle with the help of the embracing fixator. Patients have lower chance of dislocation, better limb function, and higher active hip ROM.

Trial registration: retrospectively registered.

\section{Background}

The proximal femur is the most frequent region for primary and metastatic bone tumors. Currently, surgical removal of the tumor is an important part of its comprehensive treatment. Surgical treatments include amputation and limb preserving surgery. Prosthetic replacement following tumor resection is one of the most widely used and effective methods in limb salvage surgery [1]. Because the prosthetic replacement after tumor resection can preserve limb function and improve life quality, it has gained increasing preference in treating proximal femoral tumors. The key point of the prosthetic replacement following tumor resection is seeking balance between limb function, the stability of the prosthesis and the complete clearance of the tumor. However, in order to ensure the complete clearance of involved site, surgeons are compelled to cut off the femur at a lower plane, resulting in the loss of the marker for determining the implantation angle of the prosthesis stem, which causes great difficulties in determining the accurate implantation angle of the prosthesis stem after osteotomy [2]. In general, the implantation of the prosthesis stem mainly depends on the experience of the surgeon, and the angle must be adjusted before the bone cement was completely shaped and solidified. Therefore, there is an urgent need to temporarily fix the prosthesis stem so that the surgeon can adjust the angle after implantation.

$\mathrm{Ni}$-Ti shape-memory alloys first appeared in the 1960s, which are characterized by smart mechanical properties, have been gaining increasing importance in diagnostic applications and minimal invasive 
surgery, such as the neurosurgical [3], cardiovascular [4], orthodontic fields [5] and so on. With its shapememory effect, corrosion resistance, super-elasticity, and favorable biocompatibility, nitinol has been used for internal fixation since the 1990s [6-10]. Our group designed a novel Ni-Ti shape memory alloy embracing fixator for temporary fixation in the implantation of the prosthesis stem, which has achieved favorable outcome in clinical practice. This study intends to explore the role of Ni-Ti shape memory alloy embracing fixator in determine the implantation angle of hip tumor prosthesis stem and its efficacy by comparing with traditional technique.

\section{Materials And Methods}

\section{Study Design and Patients Retrieval}

This was a retrospective observational cohort study, and the present study was approved by the Committee on Ethics of Biomedicine Research of Changhai Hospital. The medical records and radiographs of patients who presented with hip bone tumor were retrieved from May 2012 to December 2019 in our department. The inclusion criteria were: (1) proximal femur tumor treated with tumor resection and prosthetic replacement; (2) Surgeries were performed by one senior orthopaedic surgeons. The exclusion criteria: (1) pre-existing medical condition(s) that severely limited physical or mental health; (2) lost to follow-up or with incomplete medical records; (3) patients referred after failure of their primary surgery at other hospitals; (4) patients who had done other hip surgery. Out of the initial 113 hip bone tumor that were screened during the period, totally 36 patients, including 22 males and 14 females, aged from 52-72 years old were enrolled for the study, their pathological diagnoses were as follows: 4 cases of osteosarcoma, 4 cases of chondrosarcoma, 20 cases of bone metastasis, and 8 cases of giant cell tumor of bone. Their disease durations ranged from 2 months to 2 years (mean duration 0.8 years).

The 36 patients were classified into two groups: 14 had received prosthetic replacements with embracing fixators fixing at the junction of the prosthesis stem and the femur temporarily after proximal femur tumor resection and 22 had received the same replacements but without the use of embracing fixator. Results were compared between the groups that had received prosthetic replacements with or without the use of embracing fixators to assess whether the application of the embracing fixator would reduce the incidence of hip dislocation and provide better post-operational outcomes.

\section{Structure and working principles of the Ni-Ti shape memory alloy embracing fixator}

The Ni-Ti shape memory alloy embracing fixator device (Huzhou Swan Biological Memory Medical Devices Co., Ltd., Zhejiang, China) is designed based on the anatomical structure of femoral shaft and manufactured with $2 \mathrm{~mm}$-thick Ti-Ni shape memory alloy. The embracing fixator comprises o 50\%-53\% nickel, with the remainder comprising titanium. The device has six pairs compression arms that are connected to the waist. The embracing fixator is malleable at lower temperatures (martensite phase), thus, it is placed in $0-4{ }^{\circ} \mathrm{C}$ ice water for cooling before implantation. When the fixation is completed, 
$40^{\circ} \mathrm{C}-50^{\circ} \mathrm{C}$ water was used to warm the device to stimulate its memory mechanical memory functions (austenite phase), providing a continuous lateral compressive force for temporary fixation. Brief illustrations of the embracing fixator application process are shown in Fig. 1. The shape change process of the $\mathrm{Ni}$-Ti shape memory alloy embracing fixator is shown in video 1 (supplement material 1)

\section{Surgical Methods}

Preoperative MRI and PET-CT were performed to assess the extent of tumor invasion and provide basis for determining the scope of resection. All operations were performed using posterolateral hip incision. The piriform muscle and the externally rotating muscle were cut off. The capsule of the hip joint was then cut open with an $\mathrm{H}$-shaped incision (It can be resected if it is tumor-invaded). The surgical margin of osteotomy was $2-3 \mathrm{~cm}$ distal to the invasion extent of the tumor, in accordance with preoperative MRI imaging. The resection extent of soft tissue was acme distal to the reactive zone, and the extent of resection was determined again according to the result of intraoperative frozen section. The acetabular cup was biologically fixed. According to the preoperative design, we selected the appropriate femoral stem and femoral head. After implanting the prosthesis stem, a Ni-Ti memory alloy embracing fixator was used temporarily to fix between the junction of the prosthesis stem and the femur so that the fixator could keep the prosthesis stem stable. Then the prosthesis joint was reduced and moved in all directions to assess its stability. If the prosthesis joint was easily dislocated, the implantation angle of the prosthesis stem would be readjusted. When the prosthesis stem was adjusted to an optimal angle at which the prosthesis joint was the most stable and flexible, the implantation angle of the prosthesis stem was marked on the femur. Then the embracing fixator and prosthesis stem were removed. Bone cement was injected into the pulp cavity, and the prosthesis stem was inserted according to the marked angle. The prosthesis joint was reduced after coagulation of the bone cement. The prosthesis joint was moved in all directions again to observe prosthesis stability. Then the muscles around the hip joint was reconstructed in sequence before closing the incision. The external rotation muscles and the piriform muscle were fixed on the greater trochanter ring of the prosthesis, and the iliopsoas muscle was fixed on the lesser trochanter ring (Fig. 2). Detailed surgical procedure please refers to the sketch map of the application of embracing fixator in the replacement of proximal femur tumor prosthesis (Fig. 3) and the dynamic simulation of the overall process is shown in video 2 (supplement material 2). Preoperative MRI of proximal femur tumor, the resected tumor part and postoperative imaging are displayed (Fig. 4).

\section{Postoperative Management}

The patients were placed in supine position after surgery and triangular pillows were placed between the legs. The patients were told to practice muscle contraction and relaxation, as well as joint flexion and extension, turn over in bed and take deep breaths. Low-molecular-weight heparin was subcutaneous injected in all patients for 35 days to prevent thrombosis. The drainage tubes were removed in 2 to 3 days and the sutures were removed in 10 to 12 days after the operation. The patients began to practice sitting up, sitting at the bedside and standing on the floor 3 weeks postoperatively, and began to practice walking with walk aid instruments 4 weeks postoperatively. Radiotherapy and chemotherapy were also administered when needed. Professional physical therapy was suggested for all patients after being 
discharged. Post-operational follow-ups were demanded every three months for every patient, including clinical examination and imaging assessment.

\section{Clinical outcomes evaluation}

Follow-up and radiographic assessments were routinely performed at 1,3 and 6 months after prosthesis stem implantation and long-term postoperative review was conducted for 12-18 months once, the average follow-up was 14.0 (range, 12-24) months according to our team experience. Complications like hip dislocation, infection, aseptic loosening, tumor progression and procedure-related minor complications were counted between two groups in medical records. Regarding functional evaluation, the Musculoskeletal Tumor Society Scores (MSTS), Harris hip scores (HHS) and ROM were also achieved in the previous records. The MSTS score [11, 12](Musculoskeletal Tumour Society Score) is the doctorbased questionnaire which evaluates the functional condition after completed tumor treatment. This examination assesses six criteria, for the lower limb the components are pain (evaluated by VAS), function, emotional acceptance of the treatment outcome, walking, gait and need for walking aids. Among all criteria, the assessment is made from bad to very good with parallel awarding of points ( 0 to 5). Harris Hip Score is also a common functional evaluation, which has been used in the proximal femoral replacement surgery post-operative assessment [13]. Range of motion (ROM) included flexion, abduction and external rotation is evaluated after the replacement.

\section{Statistical Analysis}

Statistica squared test was used for comparison of the rate. The independent-sample t- test was used to determine the statistical significance of differences in measurement data between the two groups. We used the Chi-square test for analysis of enumeration data. $\mathrm{P}<0.05$ was considered to be statistically significant.

\section{Results}

All 36 patients received prosthetic replacements with or without the use of embracing fixators survived the perioperative period. The two patient groups presented no significant difference in age $(P=0.399)$, length of femur resection $(P=0.949)$, operation time $(P=0.664)$, blood loss $(P=0.765)$ and chemotherapy $(P=0.810)$. (Table 1) 
Table 1

Comparative features, diagnoses, and complications between groups with and without the use of embracing fixator.

\begin{tabular}{|c|c|c|c|c|}
\hline & $\begin{array}{l}\text { With embracing } \\
\text { fixator }\end{array}$ & $\begin{array}{l}\text { Without embracing } \\
\text { fixator }\end{array}$ & $\begin{array}{l}\mathrm{P} \\
\text { Value }\end{array}$ & $95 \% \mathrm{Cl}$ \\
\hline Age $(y)$ & $70.07 \pm 1.832$ & $71.95 \pm 1.320$ & 0.399 & $\begin{array}{l}-6.370 \text { to } \\
2.603\end{array}$ \\
\hline \multicolumn{5}{|l|}{ Gender } \\
\hline Men & 8 & 14 & & \\
\hline Women & 6 & 8 & & \\
\hline $\begin{array}{l}\text { Length of femoral resection } \\
(\mathrm{cm})\end{array}$ & $14.21 \pm 0.921$ & $14.14 \pm 0.774$ & 0.949 & $\begin{array}{l}-2.397 \text { to } \\
2.553\end{array}$ \\
\hline Operative time (min) & $154.8 \pm 5.864$ & $151.6 \pm 4.463$ & 0.664 & $\begin{array}{l}-11.63 \text { to } \\
18.02\end{array}$ \\
\hline Blood loss (mL) & $841.3 \pm 53.70$ & $819.0 \pm 48.01$ & 0.765 & $\begin{array}{l}-128.1 \text { to } \\
172.6\end{array}$ \\
\hline Chemotherapy & & & 0.810 & $\begin{array}{l}0.1527 \text { to } \\
4.349\end{array}$ \\
\hline Yes & 11 & 18 & & \\
\hline No & 3 & 4 & & \\
\hline Dislocation & 0 & 6 & 0.032 & $\begin{array}{l}0.0045 \text { to } \\
1.693\end{array}$ \\
\hline Infection & 0 & 1 & 0.419 & 0.0188 to 13 \\
\hline Diagnose & & & 0.059 & $\begin{array}{l}0.1569 \text { to } \\
1.045\end{array}$ \\
\hline Osteosarcoma & 2 & 2 & & \\
\hline Chondrosarcoma & 1 & 3 & & \\
\hline bone metastases & 8 & 12 & & \\
\hline Giant cell tumor & 3 & 5 & & \\
\hline
\end{tabular}

\section{Complication Occurrence}

The group that used embracing fixators during prosthetic replacements had lower incidence of hip dislocation than the group that didn't use embracing fixators. The incidence of hip dislocation in the group with the use of embracing fixators was $0 \%(0 / 14)$, compared to $27.3 \%(6 / 22)$ in the group without 
the use of embracing fixators $(P=0.032)$. The incidence of infection exhibited no significant difference between two groups: $0 \%(0 / 14)$ and $4.5 \%(1 / 22)(P=0.429)$. The incidence of aseptic loosening, and tumor progression showed no difference between groups (Table 2). Procedure-related minor complications also included 1 case of leg-length discrepancy in the group with the use of embracing fixator compared to 3 cases in the group that didn't use embracing fixator (no difference), and 1 case of deep vein thrombosis in the no embracing fixator group. (Table 2)

Table 2

Mode of failure of the prosthetic replacements with or without the use of embracing fixator.

\begin{tabular}{|c|c|c|c|c|}
\hline Complications & $\begin{array}{l}\text { With embracing } \\
\text { fixator }(n=14)(\%)\end{array}$ & $\begin{array}{l}\text { Without embracing } \\
\text { fixator }(n=22)(\%)\end{array}$ & $\begin{array}{l}\text { Total Number of } \\
\text { Patients }(n=36)\end{array}$ & $\begin{array}{l}\mathrm{P} \\
\text { Value }\end{array}$ \\
\hline \multicolumn{5}{|l|}{$\begin{array}{l}\text { Major } \\
\text { complication }\end{array}$} \\
\hline Dislocation & $0(0)$ & $6(27.3)$ & $6(16.7)$ & 0.032 \\
\hline $\begin{array}{l}\text { Aseptic } \\
\text { loosening }\end{array}$ & $0(0)$ & $0(0)$ & $0(0)$ & - \\
\hline Infection & $0(0)$ & $1(4.5)$ & $1(2.8)$ & 0.429 \\
\hline $\begin{array}{l}\text { Tumor } \\
\text { progression }\end{array}$ & 2(14.3) & $3(13.6)$ & $5(13.9)$ & 0.838 \\
\hline \multicolumn{5}{|l|}{$\begin{array}{l}\text { Minor } \\
\text { complication }\end{array}$} \\
\hline $\begin{array}{l}\text { Leg-length } \\
\text { discrepancy }\end{array}$ & $1(7.1)$ & $3(13.6)$ & $4(11.1)$ & 0.546 \\
\hline $\begin{array}{l}\text { Deep vein } \\
\text { thrombosis }\end{array}$ & $0(0)$ & $1(4.5)$ & $1(2.8)$ & 0.429 \\
\hline
\end{tabular}

\section{Functional Results and Active Hip ROM}

Patients that received prosthetic replacements with the use of embracing fixators acquired better functional scores than those without the use of embracing fixators. The MSTS93 scores were significantly higher in patients with the use of embracing fixators $(24.00 \pm 0.432 ; 80.0 \%)$ than in those without the use of embracing fixators $(21.86 \pm 0.457 ; 72.9 \%)(P=0.003)$. The two groups had no significant difference in the aspect of pain $(P=0.698)$, emotional acceptance $(P=0.452)$, support $(P=$ $0.564)$, or walking $(P=0.896)$. Patients who received prosthetic replacements with the use of embracing fixators had better performance in function and gait $(P=0.003)$. The average total HHS scores for patients treated with and without the use of embracing fixator were $85.71 \pm 1.563$ and $79.18 \pm 1.661$, respectively $(P=0.011)$. The two groups had significant difference in function scores $(38.29 \pm 0.980 \mathrm{vs}$ $32.95 \pm 1.062, P=0.002)$. The average scores for pain $(P=0.926)$ and deformity $(P=0.241)$ did not have significant differences between the two groups. Patients with the use of embracing fixators had better 
ROM of flexion ( $89.29 \pm 3.004$ vs $81.14 \pm 2.547, P=0.049)$ and abduction $(39.64 \pm 1.432$ vs $32.27 \pm 1.385$, $P=0.001)$ than patients without the use of embracing fixator. The average ROM of external rotation had no significant difference between the two groups $(28.57 \pm 1.848$ vs $26.59 \pm 1.872, P=0.480)$. (Table 3$)$

Table 3

Functional outcome scores and ROM between patients with and without the use of embracing fixator.

\begin{tabular}{|c|c|c|c|c|}
\hline & $\begin{array}{l}\text { With embracing } \\
\text { fixator }\end{array}$ & $\begin{array}{l}\text { Without embracing } \\
\text { fixator }\end{array}$ & $\begin{array}{l}\mathrm{P} \\
\text { Value }\end{array}$ & $95 \% \mathrm{Cl}$ \\
\hline MSTS (points [\%]) & $24.00 \pm 0.432(80.0 \%)$ & $21.86 \pm 0.457(72.9 \%)$ & 0.003 & $\begin{array}{l}0.774 \text { to } \\
3.500\end{array}$ \\
\hline Pain & $4.143 \pm 0.177$ & $4.027 \pm 0.131$ & 0.698 & $\begin{array}{l}-0.524 \text { to } \\
0.355\end{array}$ \\
\hline Function & $4.429 \pm 0.173$ & $3.627 \pm 0.135$ & 0.003 & $\begin{array}{l}0.259 \text { to } \\
1.144\end{array}$ \\
\hline $\begin{array}{l}\text { Emotional } \\
\text { acceptance }\end{array}$ & $3.714 \pm 0.163$ & $3.545 \pm 0.143$ & 0.452 & $\begin{array}{l}-0.282 \text { to } \\
0.620\end{array}$ \\
\hline Support & $3.929 \pm 0.165$ & $3.773 \pm 0.185$ & 0.564 & $\begin{array}{l}-0.388 \text { to } \\
0.700\end{array}$ \\
\hline Walking & $3.714 \pm 0.194$ & $3.682 \pm 0.153$ & 0.896 & $\begin{array}{l}-0.468 \text { to } \\
0.533\end{array}$ \\
\hline Gait & $4.071 \pm 0.165$ & $3.258 \pm 0.153$ & 0.003 & $\begin{array}{l}0.281 \text { to } \\
1.226\end{array}$ \\
\hline HHS & $85.71 \pm 1.563$ & $79.18 \pm 1.661$ & 0.011 & $\begin{array}{l}1.587 \text { to } \\
11.48\end{array}$ \\
\hline Pain & $39.57 \pm 1.806$ & $39.36 \pm 1.344$ & 0.926 & $\begin{array}{l}-4.299 \text { to } \\
4.714\end{array}$ \\
\hline Function & $38.29 \pm 0.980$ & $32.95 \pm 1.062$ & 0.002 & $\begin{array}{l}2.186 \text { to } \\
8.476\end{array}$ \\
\hline Deformity & $3.786 \pm 0.114$ & $3.545 \pm 0.143$ & 0.241 & $\begin{array}{l}-0.170 \text { to } \\
0.650\end{array}$ \\
\hline Range of movement & $4.071 \pm 0.195$ & $3.364 \pm 0.180$ & 0.015 & $\begin{array}{l}0.148 \text { to } \\
1.267\end{array}$ \\
\hline \multicolumn{5}{|l|}{$\mathrm{ROM}\left({ }^{\circ}\right)$} \\
\hline Flexion & $89.29 \pm 3.004$ & $81.14 \pm 2.547$ & 0.049 & $\begin{array}{l}0.028 \text { to } \\
16.27\end{array}$ \\
\hline Abduction & $39.64 \pm 1.432$ & $32.27 \pm 1.385$ & 0.001 & $\begin{array}{l}3.138 \text { to } \\
11.60\end{array}$ \\
\hline External rotation & $28.57 \pm 1.848$ & $26.59 \pm 1.872$ & 0.480 & $\begin{array}{l}-3.664 \text { to } \\
7.625\end{array}$ \\
\hline
\end{tabular}




\section{Discussion}

The proximal femur is one of the most frequent region for primary and metastatic bone tumors $[14,15]$. The invasion of the tumor and the concomitant pathological fracture have caused great suffering to the patients and seriously affected their quality of life. In the past, amputation is the dominating choice of treatment for bone tumors, which caused severe physical and psychological trauma $[16,17]$.

With the continuous improvement of surgical technique, imaging technique and pathological diagnosis, prosthetic replacement after tumor resection has become the preferred treatment for proximal femoral tumor on the basis of chemotherapy, radiotherapy and immunotherapy[18, 19]. The prosthetic replacement after tumor resection can preserve the patient's limb, relieve pain, prompt early recovery of limb function, and improve the patient's life quality significantly [20-22]. However, due to tumor invasion and severe damage of soft tissue around the bone and joint caused by the surgery, the postoperative joint stability is affected, and joint dislocation is more likely to occur than common hip replacement [23-25]. In previous studies, hip joint instability (hip dislocation) resulted in most cases of failure of proximal femur prosthetic replacement, and limb function after surgery was unsatisfactory[26]. PUCHNER S E et al reported that the general rate of dislocation following proximal femoral prosthetic replacement was $13 \%$ after an average period of $7 \pm 8$ months (range from 0.3 to 33 months) after surgery. From 1982 to 1986 the dislocation rate was about 33\% and slowly dropped to $9 \%$ in the following two decades (1987-2008) [23]. Postoperative dislocation of the hip joint causes pain to patients, increases treatment cost, and brings difficulties for the doctors. Therefore, it is of great importance to determine the accurate implantation angle of the prosthesis stem during the procedure [27, 28].

The main factors related to the joint stability after replacement include the accurate implantation angle of the prosthesis stem and the reconstruction of the soft tissue around the joint [29]. In order to remove tumor tissue as thoroughly as possible, the prosthetic replacement after tumor resection will cause more serious damage to the soft tissue around the joint than common joint replacement. Moreover, the soft tissue around the joint might not be completely and effectively reconstructed during surgery, which leads to postoperative joint dislocation. Under these circumstances, accurate implantation angle of the prosthesis stem appears to be particularly important, which requires the surgeon to ensure that the implantation angles of the acetabular cup and prosthesis stem are appropriate and accurate. To ascertain the implantation angle of the acetabular cup, the surgeons could refer to the normal acetabular angle, because typically the proximal tumor of the femur does not invade the acetabulum. There have been many studies exploring methods for positioning the acetabular cup, including the use of anatomical markers, pre-evaluation with CT scans, and three-dimensional directional monitoring[29]. However, there are few reports about the concrete procedure to determine the correct implantation angle of the prosthesis stem.

Because of the tumor invasion of the proximal femur, it is often necessary to cut off the greater trochanter and lesser trochanter during the osteotomy, thus losing the anatomical markers as the reference for implanting the prosthesis stem[30]. Surgeons usually make marks on the junction before 
resecting the involved bone, and make marks on the corresponding part of the prosthesis stem to offer reference when implanting the prosthesis stem [31,32]. After implanting the prosthesis stem, it will be fixed with bone cement. And once the prosthesis has been fixed, even if the implantation angle of the prosthesis stem is not satisfactory, the surgeon cannot readjust it, resulting in the prosthetic head and acetabular cup not being optimally matched, leading to a greater tendency towards hip joint dislocation[33, 34].

In this study, we used a novel embracing fixator made of the Ni-Ti shape memory alloy to help us determine the implantation angle of prosthesis stem. Ni-Ti alloy is a shape memory alloy with high strength, flexible plasticity, and good biocompatibility that can automatically restore its original shape at a specific temperature [35]. Thus, the embracing fixator can be artificially spread to permit surgeon to adjust prosthesis stem as required. After heating to $40^{\circ} \mathrm{C} \sim 50{ }^{\circ} \mathrm{C}$ (caused by lavaging warmed normal saline), the embracing fixator can recover the original memorized shape and contract to grasp tightly the prosthesis and the distal bone together. During the operation, we did not use bone cement to fix it after implanting the prosthesis stem immediately. Instead, we temporarily used the $\mathrm{Ni}$-Ti shape memory alloy embracing fixator to fix between the junction of the prosthesis stem and the femur to keep the prosthesis stem stable. Then the hip joint was reduced by the temporary fix and moved in all directions to assess the stability of the joint. If the surgeon felt that the implantation angle of the prosthesis stem was not ideal, he can remove the embracing fixator easily and readjust the implantation angle of the prosthesis stem. When the prosthesis stem was at the optimal implantation angle, the surgeon marked the angle of the prosthesis stem relative to the femur and then fixed the prosthesis stem with bone cement. By this way, the implantation angle of the prosthesis stem can be repeatedly tested to determine the best implantation angle of the prosthesis stem, which greatly reduces the incidence of postoperative dislocation.

In our study, we found that patients who received prosthetic replacements with the use of embracing fixators had lower rate of hip dislocation, better limb function, and greater range of active hip movement on flexion and abduction than those without the use of embracing fixators. The most significant complication is dislocation. Puchner SE et al reported in his study that $8 \%-33 \%$ of patients treated without the embracing fixators suffered dislocation[23], which is similar to our study find that $6(27.3 \%)$ patients experienced in control group. A lot of postoperative dislocations are caused by poor placement of prosthesis. In our research, we inserted the prosthesis stem according to our experience and then used the embracing fixator to fix between the junctional part of the prosthesis stem and the femur to keep the prosthesis stem stable. Then the joint was reduced and moved in multiple directions to test the stability of the joint. If dislocation occurred at a certain angle, we could remove the embracing fixator and readjust the implantation angle of the prosthesis stem until dislocation didn't occur at any angle. The use of embracing fixator allows surgeons to adjust the implantation angle of prosthesis stem repeatedly until the satisfactory angle is reached, so that the prosthesis can be optimally matched. This method could avoid the disadvantage of traditional methods in determining the implantation angle of prosthesis stem only one time, which could not be adjusted even if it is not satisfied. This is very helpful for preventing post-operational dislocation. In addition, the best matching of prosthesis can effectively accelerate the recovery of limb function and ROM of hip joint after operation[36, 37]. In this study, the MSTS and HHS 
scores for the patients with the use of embracing fixators were better than those without the use of embracing fixators $(P<0.05)$. This may be attributed to the accurate placement of the prosthesis and the absence of post-operational dislocation, which were very important for the rehabilitation of the limb function and hip joint movement.

Our study had some limitations because it was a retrospective study. Firstly, low morbidity resulted in small sample size, although we collected data covering an 8-year span. Secondly, during the 8 years of the study, the progress in surgical technique and prosthesis design might have also played a role in lowering dislocation rate and improving limb functions. These biases might affect our interpretation of the results.

\section{Conclusion}

$\mathrm{Ni}$-Ti shape memory alloy embracing fixator plays a key part in determining the accurate implantation angle of the prosthesis stem in the prosthetic replacement following the proximal femur bone tumor resection. The implantation angle of the prosthesis stem can be adjusted repeatedly with the aid of the $\mathrm{Ni}$-Ti embracing fixator, so that the prosthesis stem can be implanted at an optimal angle and the prosthetic head and the acetabular cup can be optimally matched. This technique can prevent hip dislocation effectively, with better limb function recovery and fewer complications.

\section{Abbreviations}

NiTi: nickel-titanium; ROM: Range of motion; MSTS: Musculoskeletal Tumor Society Scores; HHS: Harris hip scores; VAS: Visual Analogue Scale/Score.

\section{Declarations}

\section{Ethics approval and consent to participate:}

The Ethics Committee of Changhai Hospital approved the study. The informed consent was waived because this is a retrospective study.

\section{Consent for publication:}

The written consent is available for review by the chief editor.

\section{Availability of data and materials:}

All data analyzed during the study were included in this article.

\section{Competing interests:}

The authors declare that they have no competing interests. 


\section{Funding:}

The present research was fund by the National Natural Science Foundation of China (No. 81601910, No. 81571887 \& No. 81672134), the National Key Research and Development Program of China (2018YFB1105605), the Shanghai Rising-Star Program (No. 18QA1405400).

\section{Authors' contributions:}

SX designed the study. YW, PZ and DX collected the data and wrote the manuscript. YW and SW analyzed the data. All authors have read and approved the final manuscript.

\section{Acknowledgements:}

The authors would like to thank Mrs. Honglian Di for helping collecting clinical data.

\section{References}

1. Moura DL, Fonseca R, Freitas J, Figueiredo A, Casanova J. Reconstruction with iliac pedestal cup and proximal femur tumor prosthesis after wide resection of chondrosarcoma - 10-year follow-up results. Revista brasileira de ortopedia. 2017;52(6):748-54.

2. Hogendoorn PC, Athanasou N, Bielack S, De AE, Dei Tos AP, Ferrari S, et al. Bone sarcomas: ESMO Clinical Practice Guidelines for diagnosis, treatment and follow-up. Annals of Oncology. 2010;21(5):21-6.

3. Hoh DJ, Hoh BL, Amar AP, Wang MY. Shape memory alloys: metallurgy, biocompatibility, and biomechanics for neurosurgical applications. Neurosurgery. 2009;64(5 Suppl 2):199-214; discussion -5 .

4. Witkowska J, Sowinska A, Czarnowska E, Plocinski T, Kaminski J, Wierzchon T. Hybrid a$\mathrm{CNH}+\mathrm{TiO} 2+\mathrm{TiN}$-type surface layers produced on NiTi shape memory alloy for cardiovascular applications. Nanomedicine (Lond). 2017;12(18):2233-44.

5. Es-Souni M, Es-Souni M, Fischer-Brandies H. Assessing the biocompatibility of NiTi shape memory alloys used for medical applications. Anal Bioanal Chem. 2005;381(3):557-67.

6. Zhou PY, Jiang LQ, Xia DM, Wu JH, Ye Y, Xu SG. Nickel-titanium arched shape-memory alloy connector combined with bone grafting in the treatment of scaphoid nonunion. Eur J Med Res. 2019;24(1):27.

7. Chen X, Liu P, Zhu X, Cao L, Zhang C, Su J. Design and application of nickel-titanium olecranon memory connector in treatment of olecranon fractures: a prospective randomized controlled trial. Int Orthop. 2013;37(6):1099-105.

8. Sharma M, Sharma S. Comment on: shape memory $\mathrm{Ni}-\mathrm{Ti}$ alloy swan-like bone connector for treatment of humeral shaft nonunion. Int Orthop. 2010;34(7):1071. 
9. Poggetti A, Rosati M, Castellini I, Evangelisti G, Battistini P, Parchi P, et al. Treatment of Scaphoid Waist Nonunion Using Olecranon Bone Graft and Stryker Asnis Micro Cannulated Screw: A Retrospective Study-80 Case Studies and 6 Years of Follow-Up. J Wrist Surg. 2015;4(3):194-9.

10. Hao ZC, Xia Y, Wu JH, Zhang YT, Xu SG. Application of a Ni-Ti arched shape-memory connector in unstable lateral malleolus fractures: A retrospective study. Injury. 2019;50(2):551-7.

11. Enneking WF, Dunham W, Gebhardt MC, Malawar M, Pritchard DJ. A system for the functional evaluation of reconstructive procedures after surgical treatment of tumors of the musculoskeletal system. Clin Orthop Relat Res. 1993(286):241-6.

12. Tunn PU, Pomraenke D, Goerling U, Hohenberger P. Functional outcome after endoprosthetic limbsalvage therapy of primary bone tumours-a comparative analysis using the MSTS score, the TESS and the RNL index. Int Orthop. 2008;32(5):619-25.

13. Theil C, Mollenbeck B, Gosheger G, Schmidt-Brakling T, Andreou D, Henrichs MP, et al. Acetabular Erosion After Bipolar Hemiarthroplasty in Proximal Femoral Replacement for Malignant Bone Tumors. J Arthroplasty. 2019;34(11):2692-7.

14. Jonas SC, Mehendale SM, Bick SM, Baker RP. Current orthopaedic management of bony metastases in the proximal third of the femur. Hip International the Journal of Clinical \& Experimental Research on Hip Pathology \& Therapy. 2017;27(1).

15. Doung YC, Kenan S, Rapp T. Metastatic lesions of the proximal femur. Bulletin of the Nyu Hospital for Joint Diseases. 2011;69(1):81-6.

16. Ferrari S, Palmerini E, Staals EL, Mercuri M, Franco B, Picci P, et al. The treatment of nonmetastatic high grade osteosarcoma of the extremity: review of the Italian Rizzoli experience. Impact on the future. Cancer Treatment \& Research. 2009;152:275.

17. Scolaro JA, Lackman RD. Surgical management of metastatic long bone fractures: principles and techniques. The Journal of the American Academy of Orthopaedic Surgeons. 2014;22(2):90-100.

18. Tiwari A. Current concepts in surgical treatment of osteosarcoma. Journal of Clinical Orthopaedics \& Trauma. 2012;3(1):4.

19. Gharedaghi M, Peivandi MT, Mazloomi M, Shoorin HR, Hasani M, Seyf P, et al. Evaluation of Clinical Results and Complications of Structural Allograft Reconstruction after Bone Tumor Surgery. Archives of Bone \& Joint Surgery. 2016;4(3):236.

20. Liu T, Zhang X, Zhang Q, Zhang X, Guo X. Total femoral reconstruction with custom prosthesis for osteosarcoma. World Journal of Surgical Oncology. 2016;14(1):1-6.

21. Issack PS, Barker J, Baker M, Kotwal SY, Lane JM. Surgical management of metastatic disease of the proximal part of the femur. Journal of Bone \& Joint Surgery American Volume. 2014;96(24):20918.

22. Feng $\mathrm{H}$, Wang $\mathrm{J}, \mathrm{Xu} \mathrm{J}$, Chen $\mathrm{W}$, Zhang $\mathrm{Y}$. The surgical management and treatment of metastatic lesions in the proximal femur:A mini review. Medicine. 2016;95(28):e3892.

23. Puchner SE, Funovics PT, Hipfl C, Dominkus M, Windhager R, Hofstaetter JG. Incidence and management of hip dislocation in tumour patients with a modular prosthesis of the proximal femur. 
International orthopaedics. 2014;38(8):1677-84.

24. Kinkel S, Graage JD, Kretzer JP, Jakubowitz E, Nadorf J. Influence of stem design on the primary stability of megaprostheses of the proximal femur. International orthopaedics. 2013;37(10):1877-83.

25. Gungor HR, Kiter E, Ok N, Catak A. Osteochondral mosaicplasty along with osteochondroplasty of the femoral head in femoroacetabular impingement: a case report. Eklem hastaliklari ve cerrahisi $=$ Joint diseases \& related surgery. 2015;26(3):181-4.

26. Bickels J, Meller I, Henshaw RM, Malawer MM. Reconstruction of hip stability after proximal and total femur resections. Clinical Orthopaedics \& Related Research. 2000;375(375):218.

27. Patel RM, Stulberg SD. The rationale for short uncemented stems in total hip arthroplasty. Orthopedic Clinics of North America. 2014;45(1):19-31.

28. Ateschrang A, Weise K, Weller S, Stöckle U, Zwart PD, Ochs BG. Long-Term Results Using the Straight Tapered Femoral Cementless Hip Stem in Total Hip Arthroplasty: A Minimum of Twenty-Year FollowUp. Journal of Arthroplasty. 2014;29(8):1559-65.

29. Haq RU, Park KS, Yang HK, Lee KB, Yoon TR. Displacement of a cemented femoral stem during attempted closed reduction of a dislocated total hip arthroplasty. Journal of Arthroplasty. 2010;25(4):658.e11.

30. Gunel U, Daglar B, Gunel N. Long-term follow-up of a hip joint osteoblastoma after intralesional curettage and cement packing: a case report. Acta orthopaedica et traumatologica turcica. 2013;47(3):218-22.

31. Barrientos-Ruiz I, Ortiz-Cruz EJ, Peleteiro-Pensado M. Reconstruction After Hemipelvectomy With the Ice-Cream Cone Prosthesis: What Are the Short-term Clinical Results? Clinical orthopaedics and related research. 2017;475(3):735-41.

32. Dieckmann R, Henrichs MP, Gosheger G, Holl S, Hardes J, Streitburger A. Short-stem reconstruction for megaendoprostheses in case of an ultrashort proximal femur. BMC musculoskeletal disorders. 2014;15:190.

33. Khanuja HS, Naziri Q. Re: Dislocation after total hip arthroplasty: a randomized clinical trial of a posterior approach and a modified lateral approach. J Arthroplasty 2012;27(3):378. Journal of Arthroplasty. 2013;28(1):199-200.

34. Ng Man Sun S, Gillott E, Davies N, Skinner J. Displacement of a cemented femoral implant. A complication of manipulation of a dislocated total hip replacement. BMJ case reports. 2012;2012.

35. Chembath M, Balaraju JN, Sujata M. Surface characteristics, corrosion and bioactivity of chemically treated biomedical grade NiTi alloy. Materials science \& engineering $\mathrm{C}$, Materials for biological applications. 2015;56:417-25.

36. Min L, Peng J, Duan H, Zhang W, Zhou Y, Tu C. Uncemented allograft-prosthetic composite reconstruction of the proximal femur. Indian journal of orthopaedics. 2014;48(3):289-95.

37. Gosal GS, Boparai A, Makkar GS. Long-Term Outcome of Endoprosthetic Replacement for Proximal Femur Giant Cell Tumor. Nigerian journal of surgery : official publication of the Nigerian Surgical Research Society. 2015;21(2):143-5. 
Figures
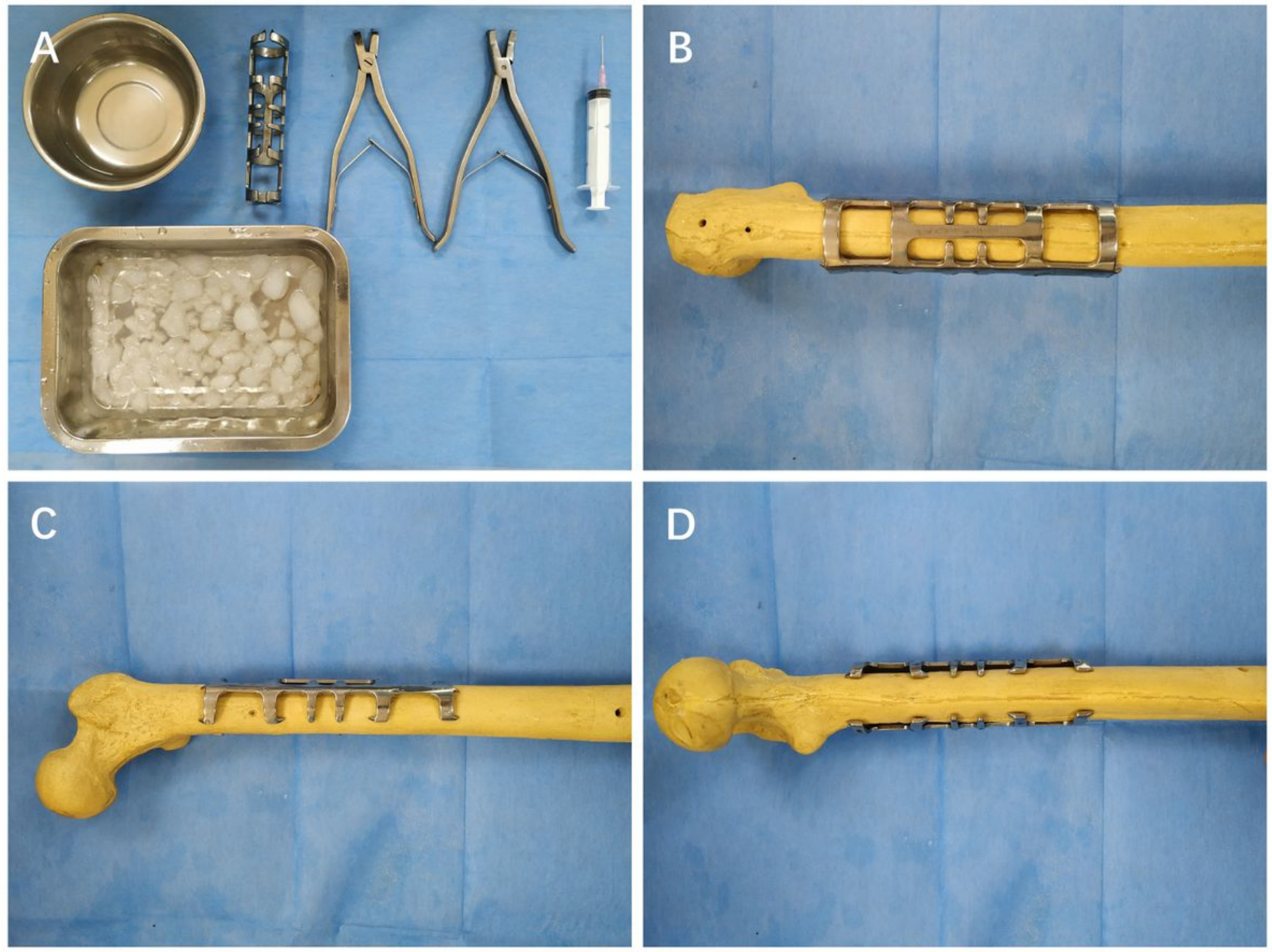

\section{Figure 1}

Brief illustrations of the embracing fixator application process. (A) Supporting equipment used by the embracing fixator. (B-D) Triangular view of the femur after the embracing fixator is implanted. 

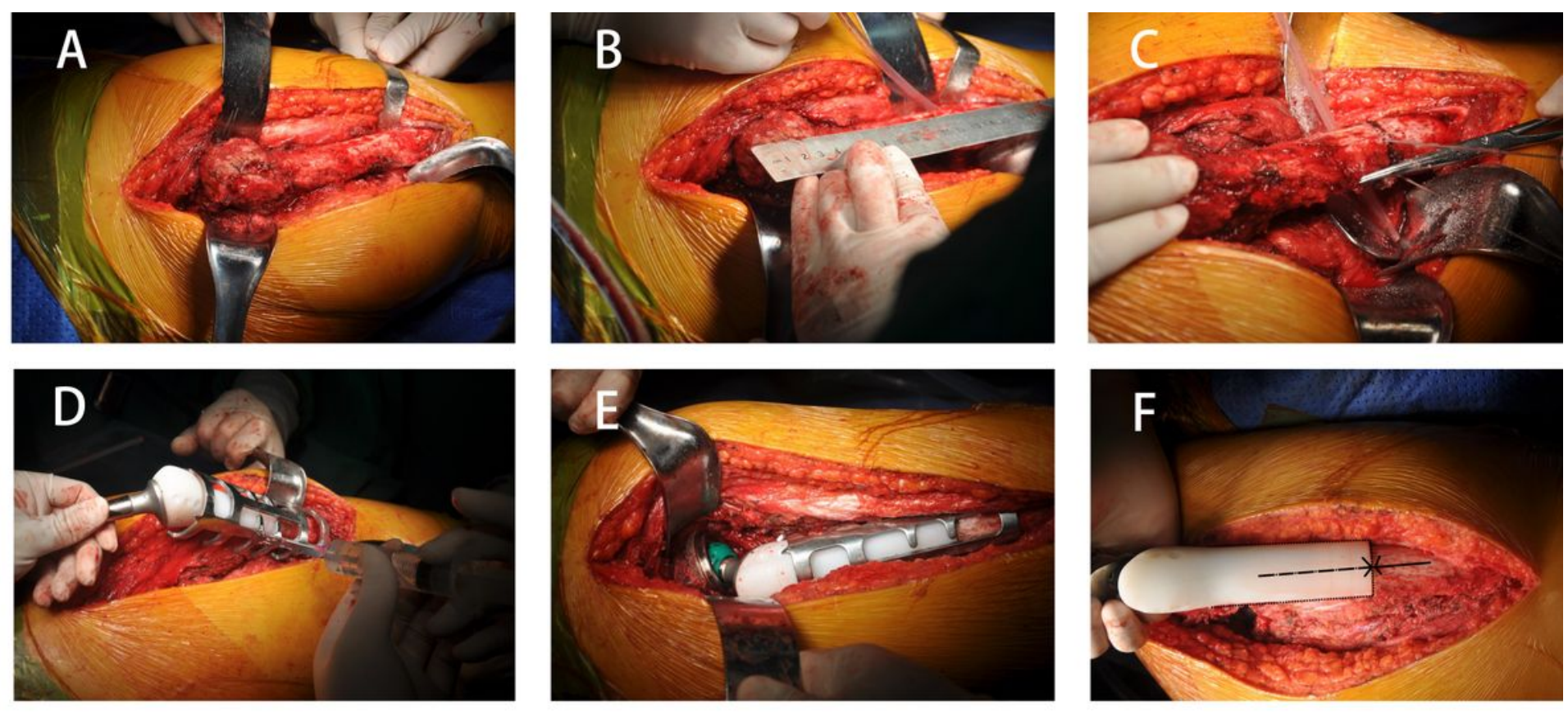

\section{Figure 2}

The application of nickel-titanium shape memory alloy embracing fixator in the replacement of tumor prosthesis. (A) The tumor of the proximal femur was exposed using the posterolateral hip incision. (B) The extent of tumor invasion and osteotomy plane were determined according to the preoperative MRI of the tumor. (C) The femur was cut at the marked plane of the osteotomy using a wire saw. (D) The nickel titanium memory alloy embracing fixator fixed between the junction of the prosthesis stem and femur. (E) The prosthesis joint was reduced and moved in all directions to assess its stability. (F) After ensuring the stability of the joint and the best matching of the femoral head and the acetabular cup, the implantation angle of the prosthesis stem relative to the femur was marked. Bone cement was then injected into the femoral medullary cavity and the prosthesis stem was inserted according to the angle marked before. After coagulation of the bone cement, the prosthesis joint was reduced. 


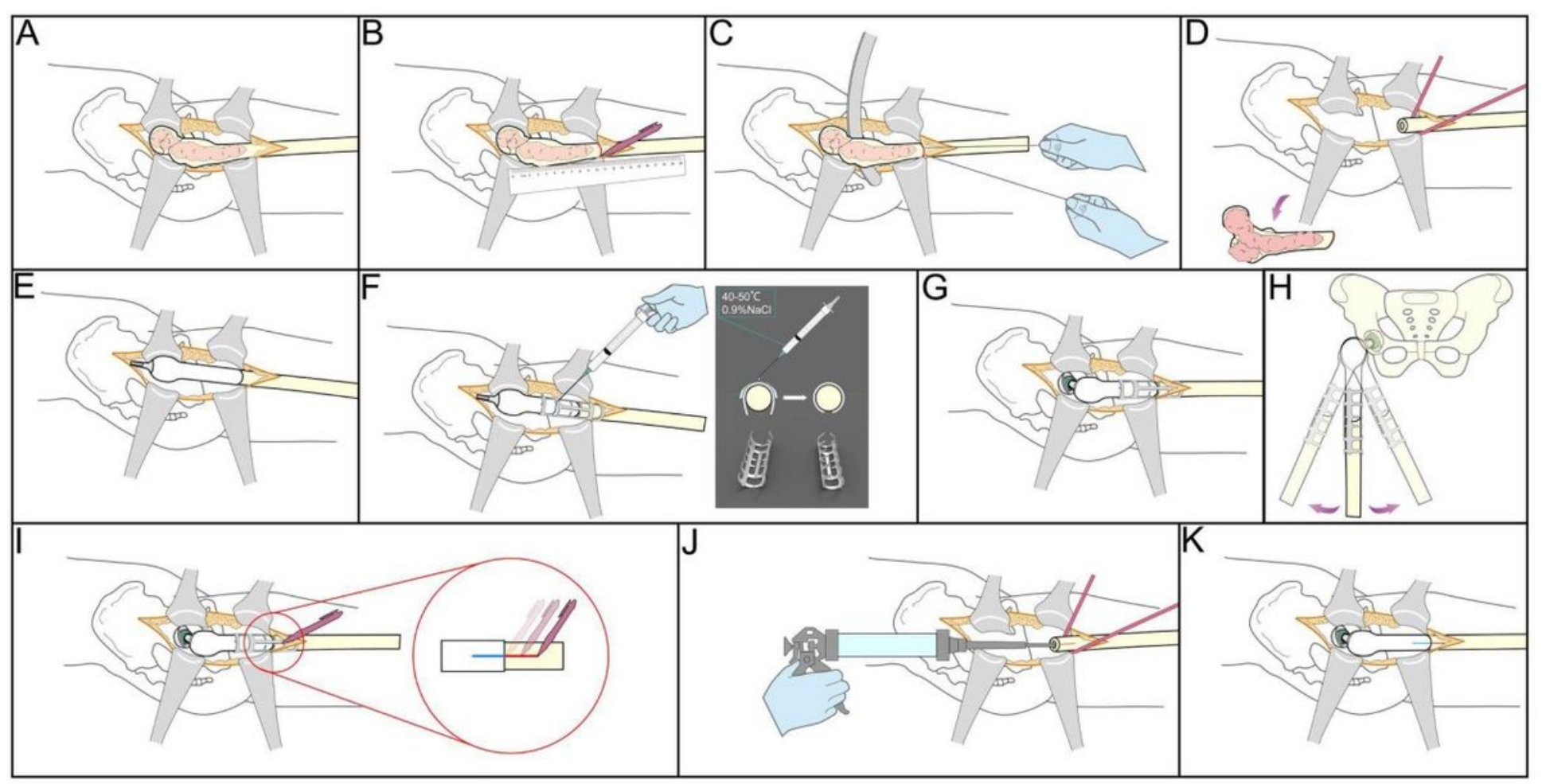

Figure 3

Sketch map of the application of nickel-titanium shape memory alloy embracing fixator in the replacement of proximal femur tumor prosthesis.
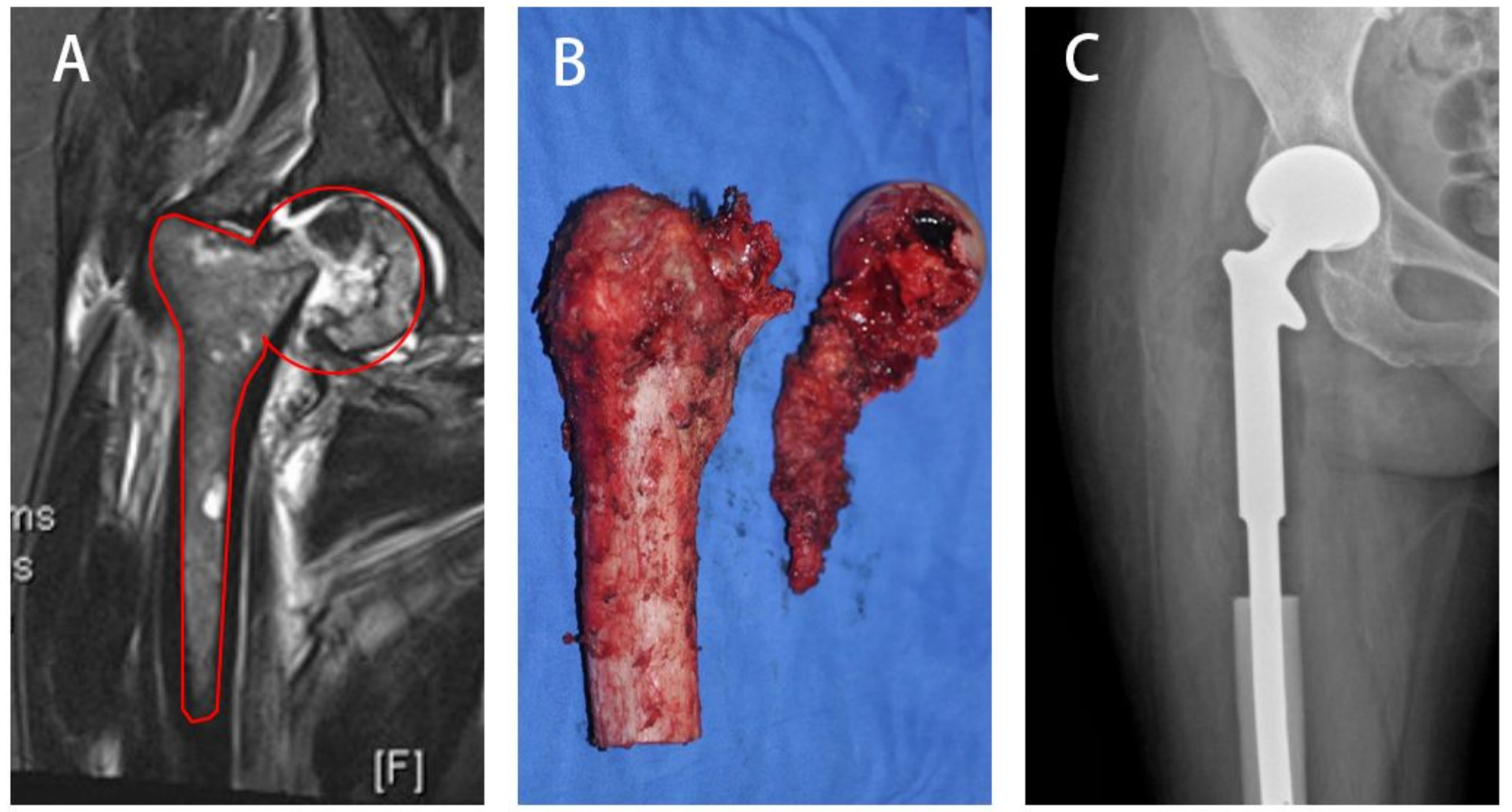

Figure 4 
(A) Preoperative MRI shows proximal femur involvement by the tumor. (B) The tumor of the proximal femur was resected. (C) Postoperative radiography data.

\section{Supplementary Files}

This is a list of supplementary files associated with this preprint. Click to download.

- 1.mp4

- 2.mp4 